\title{
Using the WHO safe childbirth checklist to improve essential care delivery as part of the district-wide maternal and newborn health quality improvement initiative, a time series study
}

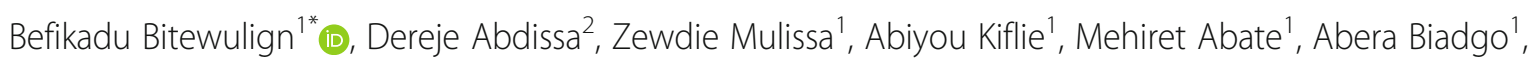
Haregeweyni Alemu', Meseret Zelalem³, Munir Kassa ${ }^{3}$, Gareth Parry ${ }^{4}$ and Hema Magge ${ }^{5,6,7}$

\begin{abstract}
Background: Care bundles are a set of three to five evidence-informed practices which, when performed collectively and reliably, may improve health system performance and patient care. To date, many studies conducted to improve the quality of essential birth care practices (EBPs) have focused primarily on provider- level and have fallen short of the predicted impact on care quality, indicating that a systems approach is needed to improve the delivery of reliable quality care.

This study evaluates the effect of integrating the use of the World Health Organization Safe Childbirth Checklist (WHO-SCC) into a district-wide system improvement collaborative program designed to improve and sustain the delivery of EBPs as measured by "clinical bundle" adherence over-time.

Methods: The WHO-SCC was introduced in the context of a district-wide Maternal and Newborn Health (MNH) collaborative quality of care improvement program in four agrarian Ethiopia regions. Three "clinical bundles" were created from the WHO-SCC: On Admission, Before Pushing, and Soon After Birth bundles. The outcome of each bundle was measured using all- or- none adherence. Adherence was assessed monthly by reviewing charts of live births.

A time-series analysis was employed to assess the effectiveness of system-level interventions on clinical bundle adherence. STATA version 13.1 was used to analyze the trend of each bundle adherence overtime.

Autocorrelation was checked to assess if the assumption of independence in observations collected overtime was valid. Prais-Winsten was used to minimize the effect of autocorrelation.

Findings: Quality improvement interventions targeting the three clinical bundles resulted in improved adherence over time across the four MNH collaborative. In Tankua Abergele collaborative (Tigray Region), the overall mean adherence to "On Admission" bundle was $86 \%$ with $\beta=1.39$ (95\% Cl; $0.47-2.32 ; P<0.005)$ on average monthly. Similarly, the overall mean adherence to the "Before Pushing" bundle in Dugna Fango collaborative; Southern
\end{abstract}

\footnotetext{
* Correspondence: bbitewulign@ihi.org; befikadub1@gmail.com

'Institute for Healthcare Improvement, Addis Ababa, Ethiopia

Full list of author information is available at the end of the article
}

(c) The Author(s). 2021 Open Access This article is licensed under a Creative Commons Attribution 4.0 International License, which permits use, sharing, adaptation, distribution and reproduction in any medium or format, as long as you give appropriate credit to the original author(s) and the source, provide a link to the Creative Commons licence, and indicate if changes were made. The images or other third party material in this article are included in the article's Creative Commons licence, unless indicated otherwise in a credit line to the material. If material is not included in the article's Creative Commons licence and your intended use is not permitted by statutory regulation or exceeds the permitted use, you will need to obtain permission directly from the copyright holder. To view a copy of this licence, visit http://creativecommons.org/licenses/by/4.0/ The Creative Commons Public Domain Dedication waiver (http://creativecommons.org/publicdomain/zero/1.0/) applies to the data made available in this article, unless otherwise stated in a credit line to the data. 
Nations, Nationalities and People's (SNNP) region was $80 \%$ with $\beta=2.3(95 \% \mathrm{Cl} ; 0.89-3.74 ; P<0.005)$ on average monthly.

Conclusion: Using WHO-SCC paired with a system-wide quality improvement approach improved and sustained quality of EBPs delivery. Further studies should be conducted to evaluate the impact on patient-level outcomes.

Keywords: Quality of care, Clinical bundle, World Health Organization safe childbirth checklist, Ethiopia, Maternal and newborn health

\section{Background}

Poor quality care during institutional births, particularly in low and middle-income countries (LMIC), has been recognized as a major contributing factor to childbirthrelated harms as care providers may fail to execute essential birth practices (EBPs) in real time [1].

The 'know-do' gap - the difference between a provider's knowledge and behavior - has often been cited as a phenomenon in care delivery, which many believe may relate to the failure to remember critical steps during clinical care [2-5].

Checklists have been used as a tool to improve healthcare worker practices to deliver high quality essential care during institutional births [6, 7]. However, evidence shows that when implemented alone they may not result in change or improvement in quality of care [4]. Furthermore, studies show that the provision of clinical guide (tools) trainings to frontline healthcare providers alone will not be sufficient to improve adherence of core clinical care practices at required level [8].

In complex health system, determining the best way to translate novel checklists to improve adherence to evidence based practices by the end users may require system redesign at multiple interconnected levels, including behavioral change interventions [9-11].

System level approach led by government engaging all levels of the health system is recommended to effectively implement effective interventions at scale in LMICs $[10,12,13]$.

To help skilled birth attendants (end-users) remember EBPs in real time and adhere to it, the World Health Organization Safe Childbirth Checklist (WHO-SCC) was developed by WHO and partners [14]. The Checklist is an organized list of evidence -based essential birth practices which guides the end-uses to pause and check at four critical points during childbirth: On Admission, Before Pushing (or before Caesarian), Soon After Birth (within $1 \mathrm{~h}$ ), and Before Discharge. The checklist was designed to address the major causes of maternal and neonatal deaths $[14,15]$.

Based on promising preliminary results to improve EBP delivery, "The Better Birth Trial"- was designed to measure the impact of the WHO-SCC. There was no significant effect found on maternal or perinatal mortality or maternal morbidity despite having positive effects on EBPs during the intervention. Furthermore, adherence to EBPs was not sustained beyond the intervention period when the coaches were absent $[16,17]$. The authors suggest that provider-level interventions may not fully translate into improved patient outcomes if not incorporated into a broader system-level improvement across facilities and referral systems.

A study implemented in Rwanda using WHO-SCC found an overall improvement in the EBPs compliance rate. Significant improvements were seen in 11 out of 29 EBPs. The reasons for low compliance to other EBPs were not identified even though clinical care providers received training on the use of WHO-SCC prior to implementation [18]. These results indicate that systems improvement efforts may be required to close remaining gaps and achieve high enough reliability of adherence to achieve change in patient outcomes.

Clinical bundles have been developed and used in improvement science efforts as an approach to achieve system level change. A clinical bundle is defined as a small set of evidence-based interventions for a defined clinical domain that when implemented together at high reliability, will result in significantly better outcomes than when implemented individually [19].

Bundles are thought to promote awareness that an entire care team must work together in a system designed for reliability. Bundles also promote the use of improvement methods to redesign care processes [19].

Using standard quality improvement (QI) methods, bundles have been found to drive performance to new levels with the theory that in order to achieve high levels of reliable bundle implementation it will require fundamental system change which lead to better and sustained results [20-24]. For instance, if each of five bundle elements are delivered at $90 \%$ reliability, then the bundle is reliably delivered at $59 \%$, as bundle reliability is the product of each element's reliability $(90 \% \times 90 \% \times 90 \% \times 90 \% \times 90 \%)$ [25]. Studies indicate that all-or-none bundle measurement can help achieve new levels of performance and improved patient outcomes [20, 26]. 
The Institute for Healthcare Improvement (IHI) in partnership with the Ethiopian Ministry of Health $(\mathrm{MOH})$ integrated the Ethiopian-adapted WHO-SCC checklist into a broader district-wide $\mathrm{MNH}$ quality of care (QoC) improvement effort, with the ultimate aim of improving QoC and reducing maternal and newborn mortality.

This study evaluates the effect of integrating the $\mathrm{MOH}$-adapted WHO-SCC into a broader district-wide system improvement collaborative program. The program was measured by clinical bundle adherence over time in four collaborative of Ethiopia's major regions: Oromia, Amhara, Southern Nations Nationalities People (SNNP), and Tigray.

\section{Methods}

\section{Program description}

The WHO-SCC was introduced in the context of a large-scale QI program being tested within the Ethiopian public health system. This intervention used a districtwide improvement collaborative designed to improve the quality of maternal and newborn health $(\mathrm{MNH})$ care. The collaborative design (Fig. 1) was based on IHI's Breakthrough Series collaborative model. The goal of the collaborative is to convene a group of facilities around accelerating improvement in a common priority area using improvement methods and an established learning network [27].

The improvement collaborative were aligned to the administrative structure of the district, and had the following basic elements: selection of priority area and target indicators, QI training for QI teams, baseline data collection, and action plans to address key gaps in essential commodities and clinical skills.

IHI was requested by the Ethiopian $\mathrm{MOH}$ to include the adapted version of WHO-SCC introduction as part of the Maternal and Newborn Health (MNH) QI effort. The adaptation was made to address major causes of maternal and neonatal morbidity and mortality in Ethiopian context. For example, does the mother/baby need to start antiretroviral drug is included as an element across the pause points.

This checklist was introduced to collaborative health care facilities during the initiation of the program as a reminder for clinical care providers to practice EBPs in real-time. The facility level end users initially used the "READ-DO" approach; read the checklist first and accomplished the EBP's. Later after earning ample experience in utilization of the checklist, they used the "Do-Confirm" approach; completed the task then read the item on the Checklist to confirm that the care is practiced and ticked. The facility QoC improvement teams designed a number of improvement projects to maximize real time utilization of the checklist. The Coaching teams included support for WHO-SCC use with patients and QI support for projects aimed to improve system performance measured by clinical bundles.

Adequate orientation for the proper use of the WHOSCC was given to facility QI teams as part of the QI initiative and implemented in line with similar studies in LMIC [18, 28, 29].

The program team collaborated with professional associations to support clinical trainings such as Helping Babies Survive (HBS) and Basic Emergency Obstetric Newborn Care (BEmONC) as needed. Subsequently, QI teams from health centers and hospitals within each district convened in a series of "learning sessions". This is intermittent face-to-face meetings with facility QI teams and leaders to share their progress, challenges, receive targeted QI support and share critical learnings from the testing process. Between learning sessions, facility teams
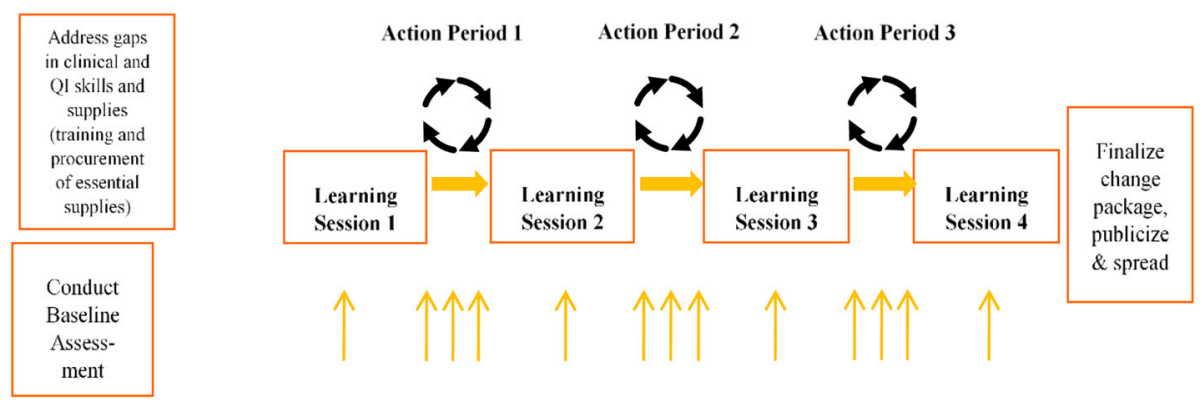

Intensive coaching to support teams to improve system and skills gaps

(visits, phone calls, engagement of program and supervisory managers, data collation \& internretation)

12-18 months

Fig. $1 \mathrm{IHI}$ 's Improvement Collaborative Design 
implemented their QI projects using the Model for Improvement (MFI) as a framework for developing, testing, and implementing changes in a system to improve process reliability and outcomes of interest [30].

Teams tested newly developed change ideas and received on-site integrated clinical/QI coaching support from joint IHI-district leadership coaches. The collaborative was organized in four sessions during a 12-15month period in the selected collaborative.

\section{Setting and site selection}

In Ethiopia, maternal and neonatal mortality remain unacceptably high at 412 deaths per 100,000 live births and 29 deaths per 1000 live births, respectively; neonatal mortality accounts for about $43 \%$ of all under- 5 deaths in Ethiopia and has had the slowest decrease over the past 16 years in comparison with the rest of child mortality [31]. These gaps are due to both utilization and quality issue, e.g. only $26 \%$ of deliveries are attended by a skilled birth attendants; and less than half of mothers receive any clinical check-up during and after delivery $[10,31]$. To address these needs, the Ethiopian Ministry of Health $(\mathrm{MoH})$ advocated for quality and equity as a core pillar in its 2015 Health Sector Transformation Plan (HSTP) [32], to achieve improved health outcomes at scale. In line with this, we co-designed the Ethiopia Healthcare Quality Initiative to accelerate health system across the country using a phased design for scale. The first phase of the program was implemented in one district improvement collaborative at Tankua Abergele, Dugna Fango, Lemmu Bilbilo and Fogera collaborative located in the regions of Tigray, SNNP, Oromia, and Amhara respectively (four of Ethiopia's most populous regions).

All facilities in each district were included to ensure a district-wide approach, which consisted of three primary hospitals and twenty-seven health centers across the four district improvement collaborative. Collaborative were selected by regional leadership based on need for improvement, lack of other MNH partner-supported initiatives and the local leadership's desire for the approach. Leaders from the collaborative also demonstrated commitment to generate honest data for improvement.

\section{Outcome measures}

In consultation with $\mathrm{MOH}-\mathrm{MNCH}$ Directorate, we designed three clinical bundles selected from the WHOSCC (Table 1). The three clinical bundles were measured using all-or-none bundle adherence (adherence $=$ yes if all bundle elements achieved) to include among the collaborative target indicators.

The selection of the clinical bundle elements to create the "all or none bundles" was made using a defined criteria's set by pool of high level clinical and quality improvement experts from Ethiopian Ministry of Health and Institute for Healthcare Improvements. The codeveloped clinical bundles are based on content derived from the standard Ethiopian protocols and WHO Safe Childbirth Checklist. Some of the criteria's used was availability of data on individual patient folder care documentation for the purpose of triangulating against the bundle element ticked on the WHO Safe Childbirth Checklist for measurement. Above all, the ability of the selected bundle to improve the general preventive care and to impact the birth outcome was considered.

The outcome measures for this study are all-or-none adherence to On Admission, Before Pushing and Soon After Birth bundles.

\section{Data collection}

The data sources included audits of WHO-SCC and medical records. In health facilities where the number of monthly deliveries were greater than 30 , a systematic random sampling method was used to retrieve 30 charts to calculate all-or-none bundle adherence using an excel template design as part of the program monitoring tool. In health centers where the number of facility births was less than 30 , the total number of monthly deliveries was selected to calculate bundle adherence.

To determine adherence to a set of checklist practices, triangulation of documented bundle element from individual patient/client folder with the Safe Childbirth checklist during the chart review process was made. If all elements have been documented on patient folder and ticked on the WHO-SCC check box, the bundle is counted as complete for that patient and is scored as "1". If any of the elements are absent either on patient documentation or not ticked on the WHO-SCC, the bundle is incomplete (no "partial credit" is given) thus it is scored " 0 ".

At the end of each month, senior project officers (SPOs), District level Quality Improvement coaches and respective facility leaders who were trained well on both the adapted WHO-SCC and the bundle data collection tool were involved in the review process. In addition, real time observation of the checklist was made by Senior Project Officers from IHI and respective system leaders during periodic joint coaching visits.

On a monthly basis, the data from respective collaborative health facilities were aggregated to create collaborative wide all- or-none bundle adherence-a dependent variable of our study.

The study period in Oromia, Tigray and SNNP was from November 2016 to December 2018. Unlike other regions, the start date of collaborative in the Amhara region was delayed by 7 months due to political instability 
Table 1 Elements of the clinical bundle extracted from $\mathrm{MOH}$ adapted Safe Childbirth Checklist

\begin{tabular}{ll}
\hline Clinical Bundles & Safe Childbirth Checklist Bundle Element \\
\hline On Admission Bundle & Danger sign assessment \\
& Partograph initiated when cervical dilation at least $4 \mathrm{~cm}$ \\
Availability of soap, water, alcohol hand rub and gloves & Birth companion encouraged to be present during labor and at birth \\
Before Pushing Bundle & Mothers privacy maintained during labor and delivery \\
Availability of gloves, soap/savlon and clean water \\
Soon After Birth Bundle (within $\mathbf{1} \mathbf{h})$ & Preparation of 10 IU IV/IM Oxytocin in syringe \\
Availability of two clean, dry, warm towels and suction device \\
Availability of bag and mask (size 0 and 1) \\
Helper/Assistant identified and informed for resuscitation \\
Newborn assessment \\
Immediate skin to skin and initiate breastfeeding within the 1st hour \\
Baby weighed and recorded \\
Administer Vitamin K1 \\
Administer tetracycline eye ointment
\end{tabular}

in the region. As the result, the study period was June 2017 to December 2018.

No baseline data were collected before the start of the intervention (study period) because the WHO-SCC was introduced for the first time as part of the quality improvement program.

\section{Analysis}

The trend of adherence to each clinical bundle over time was analyzed from the collaborative start date to the end of the project. Sustainability was assessed using a followup period of 12 months for all collaborative except Fogera (Amhara region).

For each clinical bundle, a time series analysis using STATA version 13.1 was used to assess the effect of system-level interventions on all-or-none bundle adherence over time for the four collaborative.

Durbin Watson statics-a test for autocorrelation in the residuals from a statistical regression analysis was used to check if the assumption of independence in observations collected over time was valid. To fit the purpose, monthly collaborative- wide clinical bundle adherence mean was calculated and equally spaced for respective district. Furthermore, Prais-Winsten - a procedure meant to take care of the serial correlation of type Auto -regression (AR (1)) in a linear model - was used to minimize the effect of autocorrelation.

\section{Results}

Table 2 describes the characteristics of study collaborative and the interventions. Facility-level QI teams received an average of about 20 coaching visits throughout the intervention period with some variability. This achieved the program's target which was to hold at least one joint coaching visit per month per district.

All-or-none bundle adherence to On Admission, Before Pushing, and Soon After Birth bundles in all collaborative have shown a positive monthly adherence increment (Figure 2, 3, 4). For instance, in Tigray region, Tankua Abargele collaborative, the overall mean adherence to on Admission bundle was $86 \%$ with $\beta=1.4$ (95\% CI; $0.474-2.3$ ) on average monthly (Table 3); which implies for every quality improvement intervention (QI training, learning sessions, coaching visit etc.) made across months, adherence to the on Admission bundle was increased by 1.4 .

Similarly, the overall mean adherence to Before Pushing in SNNP region, Dugna Fango collaborative was 80\% with $\beta=2.3(95 \% \mathrm{CI} ; 0.89-3.7)$ on average monthly (Table 3). This implies that for every quality improvement intervention (QI training, learning sessions, coaching visit etc.) made across months, adherence to the Before Pushing bundle adherence was increased by 1.4.

The overall mean adherence to the Soon After Birth bundle in Amhara region (Fogera collaborative) and Oromia region (Lemmu Bilbilo collaborative) was 32\% with $\beta=0.15$ (95\% CI; $-0.45-0.74)$ and $20 \%$ with $\beta=0.7$ (95\% $\mathrm{CI} ;-1.2-2.5)$ on average respectively/month (Table 3 ). This implies for every quality improvement intervention (QI training, learning sessions, coaching visit etc.) made across months, adherence to the Soon Afterbirth bundle was increased by 0.15 and 0.7 for Fogera collaborative and Lemmu Bilbilo collaborative respectively.

In addition, adherence to the clinical bundles was sustained in all collaborative beyond the intervention period (December 2017 to December 2018) (Figs. 2, 3, 4). 
Table 2 Characteristics of MNH quality improvement collaborative prototype collaborative with interventions. November 2016December 2018, Ethiopia

\begin{tabular}{|c|c|c|c|c|c|c|}
\hline Characteristics & $\begin{array}{l}\text { Tigray } \\
\text { Region }\end{array}$ & $\begin{array}{l}\text { Amhara } \\
\text { Region }\end{array}$ & $\begin{array}{l}\text { Oromia } \\
\text { Region }\end{array}$ & $\begin{array}{l}\text { SNNPR } \\
\text { Region }\end{array}$ & Mean & $\begin{array}{l}\text { Standard } \\
\text { Deviation }\end{array}$ \\
\hline District & $\begin{array}{l}\text { Tankua } \\
\text { Abargele }\end{array}$ & Fogera & $\begin{array}{l}\text { Lemmu } \\
\text { Bilbilo }\end{array}$ & $\begin{array}{l}\text { Dugna } \\
\text { Fango }\end{array}$ & & \\
\hline Total number health centers & 5 & 10 & 7 & 5 & & \\
\hline Total number primary hospitals & 1 & 0 & 1 & 1 & & \\
\hline Geographical characteristics & Agrarian & Agrarian & Agrarian & Agrarian & & \\
\hline Total population (beginning of project) & 115,841 & 296,844 & 213,032 & 122,316 & & \\
\hline Total number of learning sessions conducted & 4 & 4 & 4 & 4 & & \\
\hline Total Number of healthcare providers per collaborative & 89 & 126 & 112 & 88 & 103 & 18.5 \\
\hline Total Number of healthcare providers for childbirth per collaborative & 21 & 28 & 31 & 14 & 23 & 7.5 \\
\hline $\begin{array}{l}\text { Total Number of healthcare providers for childbirth per collaborative } \\
\text { trained on QILM* }\end{array}$ & $7(33 \%)$ & $10(36 \%)$ & $9(29 \%)$ & $7(50 \%)$ & 8 & 1.5 \\
\hline $\begin{array}{l}\text { Average number of coaching/mentoring visits received per QI team/ } \\
\text { facility/month }\end{array}$ & 2.1 & 1.3 & 1.2 & 1.8 & 1.6 & 0.42 \\
\hline $\begin{array}{l}\text { Number of health care providers trained on } \mathrm{BEmONC}^{*} \text { per } \\
\text { collaborative district }\end{array}$ & 15 & 11 & 11 & 6 & 11 & 3.6 \\
\hline $\begin{array}{l}\text { Number of health care providers trained on } \mathrm{HBS}^{*} \text { per collaborative } \\
\text { district }\end{array}$ & 16 & 30 & 24 & 15 & 21 & 7 \\
\hline Number of health care providers trained on $\mathrm{NICU}^{*}$ per hospital & 5 & 4 & 5 & 5 & 4.7 & 0.5 \\
\hline Number of system leaders trained on QILM per collaborative & 8 & 12 & 10 & 8 & 9.5 & 1.9 \\
\hline $\begin{array}{l}\text { Total number of Skilled birth attendance (Sep-2016-June 2018) per } \\
\text { collaborative }\end{array}$ & 4453 & 7410 & 7468 & 7166 & 6624 & 1453 \\
\hline $\begin{array}{l}\text { Total number of Skilled birth attendance (Sep-2016-June 2018) per } \\
\text { Hospital }\end{array}$ & 1574 & $0^{*}$ & 2734 & 2017 & 1581 & 1157 \\
\hline
\end{tabular}

*BEmONC Basic Emergency Obstetrics and Newborn Care *HBS Helping Baby Survive *NICU Neonatal Intensive Care Unit *QILM Quality Improvement and Leadership Management ${ }^{*} 0$ - There is no primary Hospital in Fogera Collaborative

\section{Discussion}

To the best of our knowledge, using the all-or-none bundle approach to measure adherence to evidencebased EBPs extracted from the WHO-SCC is the first of its kind. System- level interventions through the integration of the WHO-SCC into the district-wide MNH QI collaborative program has led to a marked increase in delivery of EBPs over time.

This has been made evident by improved adherence to On Admission, Before Pushing and Soon After Birth bundles both during the intervention period and for 12 months after the intervention period. The sustained improvement could indicate integration of changes into the routine system and ownership of the quality improvement approach.

Our study has several strengths. A standardized WHO-SCC was used to facilitate quality care in the context of a guided approach with clinical mentorship, measurement introduction, data collection, monitoring and response in a variety of health facilities across a large geographic area of rural Ethiopia. Monthly data was collected allowing for a time-series analytic approach, which can be a rigorous way of assessing change using routine programmatic data.
The On Admission and Before Pushing bundles were highly reliable in all study collaborative. However, a marked drop in adherence to the Soon after birth bundle was observed from October 2017-December 2017 at Lemmu Bilbilo, which we believe was due to political instability in the district which caused disruption in the supply chain of Vitamin K and tetracycline eye ointment from the regional capital to the district.

One possible explanation for the higher levels of reliability of the On Admission and Before Pushing bundles could be due to the fact that elements in both bundles like liquid soap, gloves and others are available in health facilities store and accessible from local markets. During the baseline assessment, oxytocin is over stocked in most facilities whereas stock of Vitamin K, TTC eye ointment was sub optimal. Due to low demand from health facilities' the national level stock of Vitamin $\mathrm{K}$ is low compared to other essential drugs which might be related to low habit of Vitamin $\mathrm{K}$ demand request by health facilities. In addition, the private drug venders have low stock of Vitamin $\mathrm{K}$ due to low demand in the market.

All-or-none adherence to the Soon After Birth bundle across all regions took a considerable time to achieve a higher level of reliability. This is primarily due to the 


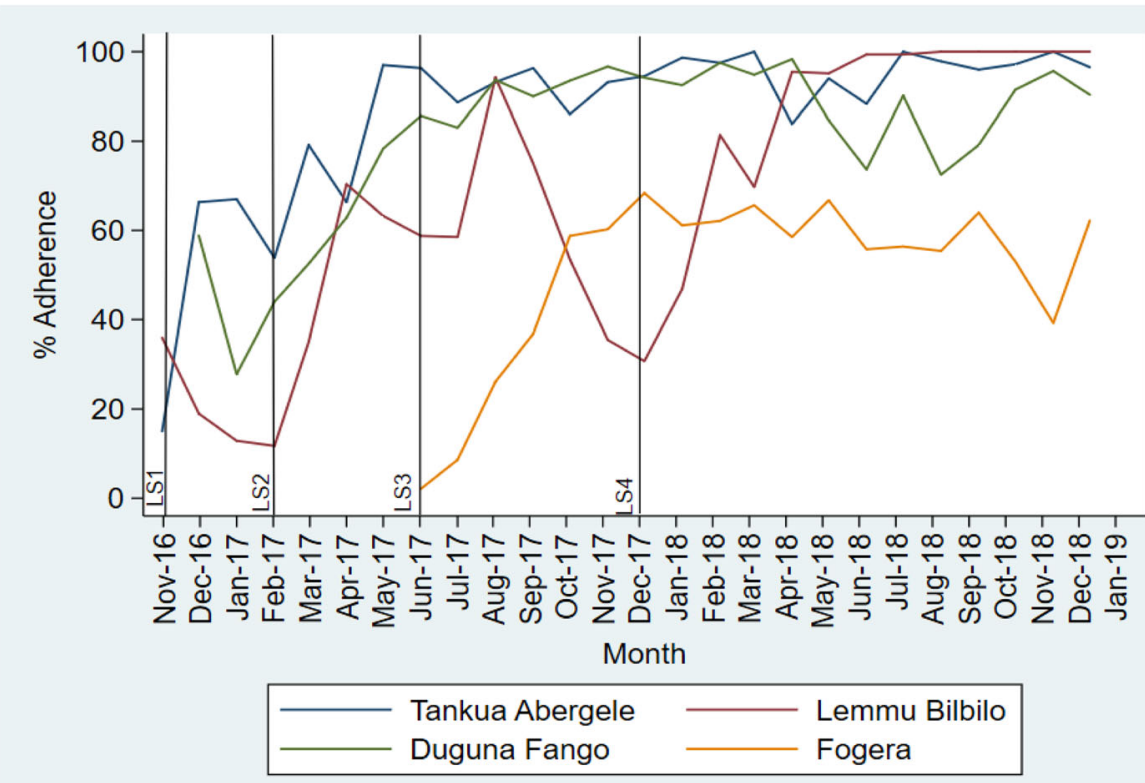

*LS1=Learning Session-1 *LS2=Learning Session 2 *LS3=Learning Session -3 * LS4=Learning Session-4

Fig. 2 Trend of all or none bundle adherence to On Admission bundle across the four collaborative. ${ }^{*} \mathrm{LS} 1=$ Learning Session $1{ }^{*} \mathrm{LS} 2=\mathrm{Learning}$ Session $2 *$ LS3 = Learning Session $3 *$ LS4 = Learning Session 4

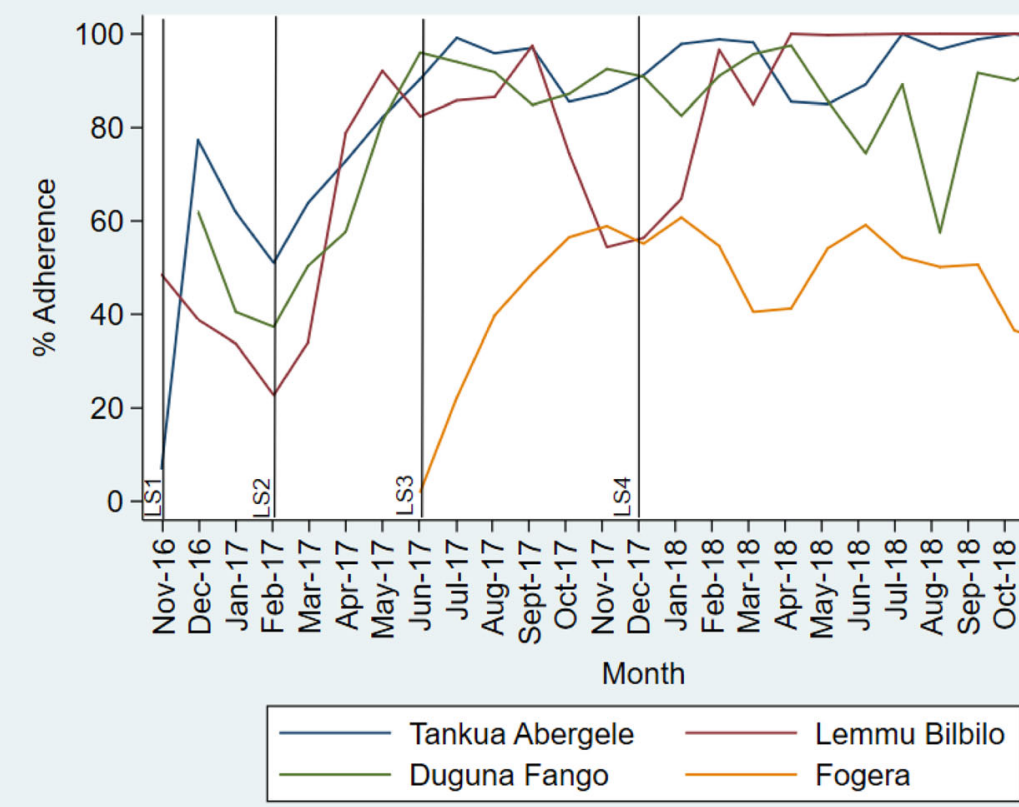

*LS1=Learning Session-1 *LS2=Learning Session 2 *LS3=Learning Session -3 *LS4= Learning Session-4

Fig. 3 Trend of all or none bundle adherence to Before Pushing bundle across the four collaborative. *LS1 = Learning Session 1 *LS2=Learning Session $2 *$ LS3 $=$ Learning Session $3 *$ LS4 = Learning Session 4 


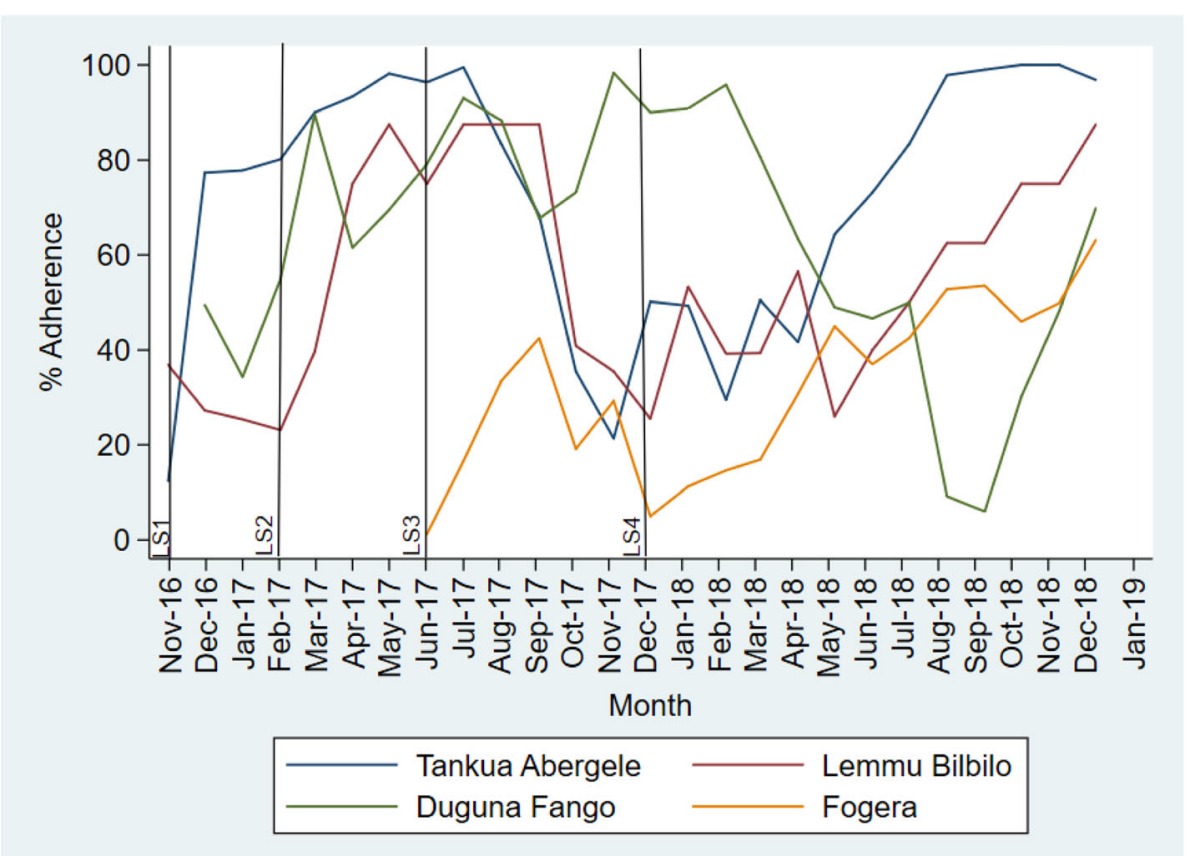

*LS1=Learning Session-1 *LS2=Learning Session 2 *LS3=Learning Session -3 *LS4= Learning Session-4

Fig. 4 Trend of all or none bundle adherence to Soon After Birth bundle across the four collaborative. *LS1 = Learning Session $1 *$ LS2 = Learning Session $2 *$ LS3 $=$ Learning Session $3 *$ LS4 = Learning Session 4

shortage of Vitamin $\mathrm{K}$ and the lengthy procurement process to purchase Vitamin $\mathrm{K}$ from private drug vendors. In response, facility QI teams have shifted focus of QI efforts onto supply chain measurement as a result significant improvement was observed after the period of low compliance (October-December 2017) across all collaborative.

Following the introduction of the WHO-SCC in the $\mathrm{MNH}$ QoC improvement collaborative facilities, the health care workers were able to identify and document newborns with complications and initiate higher level care in the effort to reduce mortality, a common recommendation of many studies [33-35]. This, in turn, led to the establishment of level II neonatal intensive care units (NICU) and implementation of feasible evidence-based interventions such as kangaroo mother care at 3 primary Hospitals of the three collaborative.

While we used bundle adherence to reliably improve EBPs extracted from the WHO-SCC, adherence to individual EBPs also significantly improved during the intervention period and was consistent with other studies [6, 18 , 36, 37]. However, unlike other studies [16, 17], adherence to EBPs was sustained in our program beyond the intervention period.

This could be attributed to the engagement of local leadership from the baseline assessment to the fourth learning session, enablement of local ownership via joint coaching visits, ensuring local relevance and acceptability by running multiple Plan-Do-Study-Act cycles (PDSAs) before initial implementation of the WHOSCC, and creating the intrinsic motivation of the endusers for successful adaptation of the WHO-SCC. This comprehensive behavior change strategy facilitated by our program has led to habits of continuous QI across the system as evidenced by incremental and sustained adherence to the three clinical bundles over time.

Our study has a number of limitations. Due to feasibility constraints and the nature of the quality improvement methodology in which QI teams ideally own the data collection and analysis themselves, we were limited to the use of routinely available data.

Comparison facilities were not included in this study due to feasibility. Finally, due to the small volume of facilities, measuring impact on neonatal mortality was not feasible, and is the subject of a larger program evaluation.

\section{Conclusion}

Embedding the use of the WHO-SCC with rigorous measures and system improvement methods to address system gaps beyond the individual provider-patient interaction could be a promising approach to improving the delivery of essential $\mathrm{MNH}$ interventions. Further 


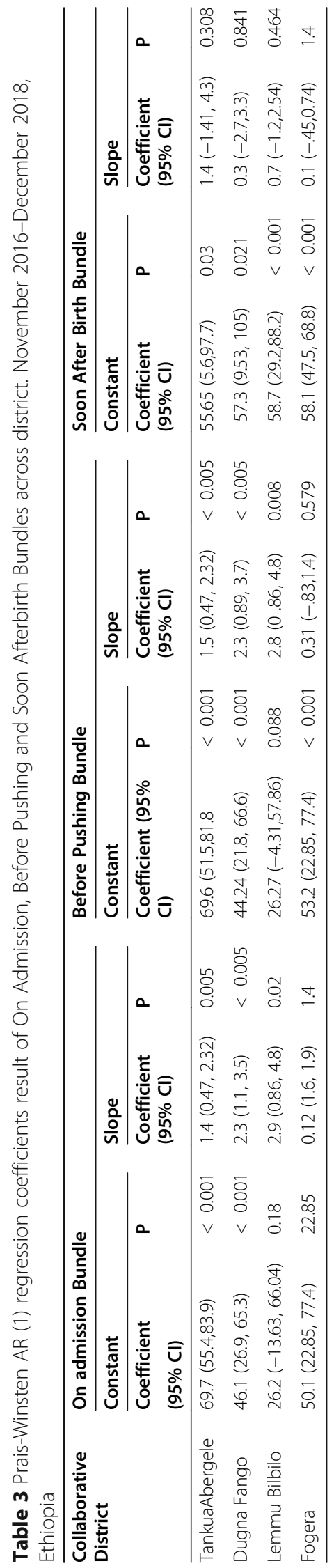


study is underway to evaluate impact on patient-level outcomes.

\section{Abbreviations}

AC: Autocorrelation; BEmONC: Basic emergency obstetric and newborn care: EBP: Essential birth practice; MOH: Ministry of Health; HBS: Helping Babies Survive; IHI: Institute for Healthcare Improvement; LMIC: Low and middle income countries; MFI: Model for Improvement; MNH: Maternal and newborn health; QILM: Quality improvement, leadership and management; QI: Quality improvement; QoC: Quality of care; SNNP: Southern Nations Nationalities and People; WHO-SCC: World Health Organization Safe Childbirth Checklist

\section{Acknowledgements}

First and foremost, praises and thanks to God, the Almighty, for His showers of blessings throughout our work to complete the manuscript successfully. We would like to express our deep and sincere gratitude to Professor Alemayehu Worku, Professor Yemane Berhane, Dr. Jane Roessner and Samir Awol for providing priceless technical guidance on the methodology and data analysis which enabled us to present this work as clearly as possible. Their dynamism, vision, sincerity and motivation have deeply inspired us. We extend our heartfelt thanks to Naomi Fedna for her unreserved support throughout the process. Finally, special thanks goes to the health workers, system leaders, mothers and newborns who allowed us to learn from them.

\section{Authors' contributions}

BB and DA contributed to conceptualized the study, managed the data, performed data analysis and wrote the first draft of the manuscript. HM and GP contributed to the development of the research questions, reviewed the data analytical methods, and contributed to writing the manuscript. ZM, AK, $M A, A B, H A, M Z$, and $M K$ reviewed and commented on the subsequent versions of the manuscript. All authors have read and approved the final manuscript.

\section{Funding}

We received no specific funding for this work.

\section{Availability of data and materials}

The datasets used during the current study are available from the Institute for Healthcare.

Improvement on reasonable request.

\section{Declarations}

\section{Ethics approval and consent to participate}

This research is part of a broader evaluation study that was reviewed and approved by Ethiopian Public Health Association (EPHA) Scientific and Ethical Review Committee. A letter of support was obtained from IHI Ethiopia project office.

\section{Consent for publication}

Not applicable.

\section{Competing interests}

We declare that we have no competing interests in this section.

\begin{abstract}
Author details
IInstitute for Healthcare Improvement, Addis Ababa, Ethiopia. ${ }^{2}$ Oromia Regional Health Bureau, Addis Ababa, Ethiopia. ${ }^{3}$ Minstry of Health-Ethiopia, Addis Ababa, Ethiopia. ${ }^{4}$ Department of Plastic and Oral Surgery, Boston Children's Hospital, Boston, MA, USA. ${ }^{5}$ Bill and Melinda Gates Foundation, Seattle, USA. ${ }^{6}$ Division of Global Health Equity, Brigham and Women's Hospital, Boston, MA, USA. 7Division of General Pediatrics, Boston Children's Hospital, Boston, MA, USA.
\end{abstract}

Received: 1 August 2020 Accepted: 6 July 2021

Published online: 16 August 2021

\section{References}

1. Spector JM, Lashoher A, Agrawal P, Lemer C, Dziekan G, Bahl R, et al. Designing the WHO safe childbirth checklist program to improve quality of care at childbirth. Int J Gynaecol Obstet. 2013;122(2):164-8. https://doi.org/1 0.1016/.j.jgo.2013.03.022

2. Dieckmann P, Reddersen S, Wehner T, Rall M. Prospective memory failures as an unexplored threat to patient safety: results from a pilot study using patient simulators to investigate the missed execution of intentions. Ergonomics. 2006;49(5-6):526-43, 526, DOl: https://doi.org/10.1080/0014013 0600568782.

3. Kuhlmann S, Piel M, Wolf OT. Impaired memory retrieval after psychosocial stress in healthy young men. J Neurosci. 2005;25(11):2977-82. https://doi. org/10.1523/JNEUROSCI.5139-04.2005.

4. Cooper J, Newbower R, Long C, McPeek B. Preventable anesthesia mishaps: a study of human factors*. Qual Saf Health Care. 2002;11(3):277-82. https:// doi.org/10.1136/ghc.11.3.277.

5. Marcus R. Human factors in pediatric anesthesia incidents. Pediatr Anesth. 2006;16(3):242-50. https://doi.org/10.1111/j.1460-9592.2005.01771.x.

6. Perry WRG, Nejad SB, Tuomisto K, Kara N, Roos N, Dilip TR, et al. Implementing the WHO safe childbirth checklist: lessons from a global collaboration. BMJ Glob Health. 2017;2(3):e000241. https://doi.org/10.1136/ bmjgh-2016-000241.

7. Spector JM, Agrawal P, Kodkany B, Lipsitz S, Lashoher A, Dziekan G, et al. Improving quality of Care for Maternal and Newborn Health: prospective pilot study of the WHO safe childbirth checklist program. PLoS One. 2012; 7(5):e35151. https://doi.org/10.1371/journal.pone.0035151.

8. Rowe AK, Onikpo F, Lama M, Osterholt DM, Rowe SY, Deming MS. A multifaceted intervention to improve health worker adherence to integrated Management of Childhood Illness Guidelines in Benin. Am J Public Health. 2009;99(5):837-46. https://doi.org/10.2105/AJPH.2008.134411.

9. Bosk CL, Dixon-Woods M, Goeschel CA, Pronovost PJ. Reality check for checklists. Lancet. 2009;374(9688):444-5. https://doi.org/10.1016/S0140-673 6(09)61440-9.

10. Kruk ME, Gage AD, Arsenault C, Jordan K, Leslie HH, Roder-DeWan S, et al. High-quality health systems in the sustainable development goals era: time for a revolution. Lancet Glob Health. 2018;6(11):e1 196-252. https://doi.org/1 0.1016/S2214-109X(18)30386-3.

11. Grol R, Grimshaw J. From best evidence to best practice: effective implementation of change in patients' care. Lancet. 2003 Oct 11;362(9391): 1225-30. https://doi.org/10.1016/S0140-6736(03)14546-1.

12. Organization WH, Development $\mathrm{O}$ for $\mathrm{EC}$ and, Development IB for $\mathrm{R}$ and. Delivering quality health services: a global imperative for universal health coverage. Delivering quality health services: a global imperative for universal health coverage. 2018 [cited 2021 Apr 18]; Available from: https://apps.who. int/iris/handle/10665/272465

13. Medicine NA of S Engineering, and, Division $\mathrm{H}$ and $\mathrm{M}$, Services B on $\mathrm{HC}$, Health B on G, Globally C on I the Q of HC. Crossing the Global Quality Chasm: Improving Health Care Worldwide: National Academies Press; 2019. 399 p

14. Organization WH. WHO safe childbirth checklist implementation guide: improving the quality of facility-based delivery for mothers and newborns: World Health Organization; 2015. p. 61.

15. Effectiveness of the WHO Safe Childbirth Checklist program in reducing severe maternal, fetal, and newborn harm in Uttar Pradesh, India: study protocol for a matched-pair, cluster-randomized controlled trial - Trials [Internet]. [cited 2018 Nov 12]. Available from: https://www.ncbi.nlm.nih. gov/pmc/articles/PMC5142140/

16. Semrau KEA, Hirschhorn LR, Marx Delaney M, Singh VP, Saurastri R, Sharma $\mathrm{N}$, et al. Outcomes of a coaching-based WHO safe childbirth checklist program in India. N Engl J Med. 2017;377(24):2313-24. https://doi.org/10.1 056/NEJMoa1701075.

17. Delaney MM, Maji P, Kalita T, Kara N, Rana D, Kumar K, et al. Improving adherence to essential birth practices using the WHO safe childbirth checklist with peer coaching: experience from 60 public health facilities in Uttar Pradesh, India. Global Health Sci Pract. 2017:5(2):217-31.

18. Tuyishime E, Park PH, Rouleau D, Livingston P, Banguti PR, Wong R. Implementing the World Health Organization safe childbirth checklist in a district Hospital in Rwanda: a pre- and post-intervention study. Matern Health Neonatol Perinatol. 2018;4 [cited 2018 Nov 10]; Available from: https://www.ncbi.nlm.nih.gov/pmc/articles/PMC5883338/.

19. IHIUsingCareBundlesWhitePaper2012-1.pdf [Internet]. [cited 2019 Mar 22]. Available from: https://emergencylaparotomy.org.uk/wp-content/uploads/2 015/11/IHIUsingCareBundlesWhitePaper2012-1.pdf 
20. Bloom FJ, Graf T, Anderer T, Stewart WF. Redesign of a diabetes system of care using an all-or-none diabetes bundle to build teamwork and improve intermediate outcomes. Diabetes Spectrum. 2010;23(3):165-9. https://doi. org/10.2337/diaspect.23.3.165.

21. Lavallée JF, Gray TA, Dumville J, Russell W, Cullum N. The effects of care bundles on patient outcomes: a systematic review and meta-analysis. Implement Sci. 2017;12(1):142. https://doi.org/10.1186/s13012-017-0670-0.

22. Bird D, Zambuto A, O'Donnell C, Silva J, Korn C, Burke R, et al. Adherence to ventilator-associated pneumonia bundle and incidence of ventilatorassociated pneumonia in the surgical intensive care unit. Arch Surg. 2010; 145(5):465-70. https://doi.org/10.1001/archsurg.2010.69.

23. Koek MBG, Hopmans TEM, Soetens LC, Wille JC, Geerlings SE, Vos MC, et al. Adhering to a national surgical care bundle reduces the risk of surgical site infections. PLoS One. 2017;12(9):e0184200. https://doi.org/10.1371/journal. pone. 0184200

24. Batura D, Hashemzehi T, Colemeadow J. A care bundle to improve perioperative mitomycin use in non-muscle-invasive bladder cancer. Int Urol Nephrol. 2018;50(6):1053-9. https://doi.org/10.1007/s11255-018-1863-4.

25. IHI_How-to-Guide Prevent Obstetrical Adverse Events.pdf [Internet]. [cited 2019 Jan 20]. Available from: https://health.usf.edu/nocms/publichealth/ chiles/fpqc/resources/HI_How-to-Guide\%20Prevent\%200bstetrical\%20A dverse\%20Events.pdf

26. Nolan T, Berwick DM. All-or-none measurement raises the bar on performance. JAMA. 2006;295(10):1168-70. https://doi.org/10.1001/jama.295.10.1168.

27. Improvement IHI. The breakthrough series: IHI's collaborative model for achieving breakthrough improvement; 2003.

28. Kabongo L, Gass J, Kivondo B, Kara N, Semrau K, Hirschhorn LR. Implementing the WHO Safe Childbirth Checklist: lessons learnt on a quality improvement initiative to improve mother and newborn care at Gobabis District Hospital, Namibia. BMJ Open Qual. 2017;6(2) [cited 2018 Nov 10] Available from: https:/www.ncbi.nlm.nih.gov/pmc/articles/PMC5574260/.

29. Kara N, Firestone R, Kalita T, Gawande AA, Kumar V, Kodkany B, et al. The BetterBirth program: pursuing effective adoption and sustained use of the WHO safe childbirth checklist through coaching-based implementation in Uttar Pradesh, India. Glob Health Sci Pract. 2017;5(2):232-43. https://doi. org/10.9745/GHSP-D-16-00411.

30. The Improvement Guide: A Practical Approach to Enhancing Organizational Performance, 2nd Edition [Internet]. Wiley.com. [cited 2019 Jun 6]. Available from: https://www.wiley.com/en-us/The+Improvement+Guide\%3A+A+Pra ctical+Approach+to+Enhancing+Organizational+Performance\%2C+2nd+ Edition-p-9780470192412

31. CSA/Ethiopia CSA-, ICF. Ethiopia Demographic and Health Survey 2016. 2017 Jul 1 [cited 2021 Apr 18]; Available from: https://www.dhsprogram. com/publications/publication-FR328-DHS-Final-Reports.cfm

32. HSTP Final Print 2015-11-27 Print size.pdf [Internet]. [cited 2021 Apr 18]. Available from: https://ehia.gov.et/sites/default/files/Resources/HSTP\%20Fina 1\%20Print\%202015-11-27\%20Print\%20size.pdf

33. Small babies, big numbers: global estimates of preterm birth - The Lancet Global Health [Internet]. [cited 2019 Apr 16]. Available from: https://www. thelancet.com/journals/langlo/article/PIIS2214-109X(18)30484-4/fulltext

34. Chawanpaiboon S, Vogel JP, Moller A-B, Lumbiganon P, Petzold M, Hogan $D$, et al. Global, regional, and national estimates of levels of preterm birth in 2014: a systematic review and modelling analysis. Lancet Glob Health. 2019; 7(1):e37-46. https://doi.org/10.1016/S2214-109X(18)30451-0.

35. WHO | Every Newborn Action Plan. WHO. [cited 2019 Aug 21]. Available from: http://www.who.int/maternal_child_adolescent/newborns/everynewborn/en/

36. Senanayake HM, Patabendige M, Ramachandran R. Experience with a context-specific modified WHO safe childbirth checklist at two tertiary care settings in Sri Lanka. BMC Pregnancy Childbirth. 2018;18(1):411. https://doi. org/10.1186/s12884-018-2040-6.

37. Walker D, Otieno P, Butrick E, Namazzi G, Achola K, Merai R, et al. Effect of a quality improvement package for intrapartum and immediate newborn care on fresh stillbirth and neonatal mortality among preterm and lowbirthweight babies in Kenya and Uganda: a cluster-randomised facilitybased trial. Lancet Glob Health. 2020;8(8):e1061-70. https://doi.org/10.1016/ S2214-109X(20)30232-1.

\section{Publisher's Note}

Springer Nature remains neutral with regard to jurisdictional claims in published maps and institutional affiliations.

Ready to submit your research? Choose BMC and benefit from:

- fast, convenient online submission

- thorough peer review by experienced researchers in your field

- rapid publication on acceptance

- support for research data, including large and complex data types

- gold Open Access which fosters wider collaboration and increased citations

- maximum visibility for your research: over $100 \mathrm{M}$ website views per year

At BMC, research is always in progress.

Learn more biomedcentral.com/submissions 